\title{
El concepto de información: dimensiones bibliotecológica, sociológica y cognoscitiva
}

\author{
Jaime Ríos Ortega *
}

Artículo recibido:

30 de enero de 2013.

Artículo aceptado:

3 de octubre de 2013.

\section{Resumen}

El término información se convirtió en un concepto esencial para la bibliotecología y otras disciplinas afines. El significado adecuado de este vocablo depende necesariamente del contexto epistémico en que se utiliza. Por otra parte, su carácter intrateórico y polisémico ha multiplicado los sentidos en que se ha utilizado, como es el caso de la teoría de la información, la sociedad red, las sociedades del conocimiento, la teoría de sistemas, la psicología cognoscitiva y, por supuesto, la bibliotecología. Sin embargo, el análisis que se hace en este artículo demuestra la necesidad de precisar el significado con el cual ha de aplicarse, principalmente dentro de la bibliotecología y las disciplinas afines, con

Instituto de Investigaciones Bibliotecológicas y de la Información de la UNAM. jrios@ibi.unam.mx

INVESTIGACIÓN BIBLIOTECOLÓGICA, Vol. 28, Núm.62, enero/abril, 2014, México, ISSN: 0187-358X. pp. 143-179 
objeto de no degradar o simplificar al máximo la utilidad teórica requerida en la construcción de modelos explicativos. En este artículo también se prueba que el significado de este término tiende a estabilizarse, aunque necesariamente articulado a las entidades teóricas de la disciplina y no más como un término teórico aislado.

Palabras clave: Información; Teoría Bibliotecológica; Información y Sociedad.

\section{Abstract}

The concept of information in library, sociological and cognitive sciences

Jaime Ríos-Ortega

The term information has become an essential concept in the field of library science and associated disciplines. The proper meaning of this term necessarily depends on epidemiological context. Moreover, its intra-theoretical and polysemic potential has led the term to be used in multiple senses, ranging from the context of cognitive psychology and, of course, to library science; however, the analysis offered herein underscores the need to define the term more precisely for use in library science and associated fields, so that its meaning is neither degraded nor over-simplified when building useful explicative models. This paper also shows that the meaning of this term has tended to stabilize as required by theoretical models in which it is used, though as an isolated theoretical term it retains a degree of ambiguity.

Keywords: Information; Library Science Theory; Information and Society.

\section{INTRODUCCIÓN}

$\mathrm{E}^{\mathrm{i}}$ concepto de información es cada vez más ubicuo y lo mismo ha suCedido con las tecnologías que la procesan. Tanto una como las otras, han sido protagonistas indiscutibles de la escena mundial desde hace varias 
décadas, así como en las comunidades académicas nacionales e internacionales. Por otra parte, la irrupción de la teoría de la información y el desarrollo tecno-científico que la ha acompañado han impactado de múltiples modos a la sociedad, así como a la cultura y la ciencia en todas sus manifestaciones y disciplinas. En consecuencia, la bibliotecología no ha sido la excepción y lejos de estar exenta de su influencia ha debido reconfigurar sus modelos teóricos explicativos y normativos con base en la teoría de la información, las tecnologías que la acompañan, así como con los enfoques sociales, lingüísticos y cognoscitivos que han desarrollado análisis y propuestas a partir del término información.

En este artículo se identifican las corrientes de pensamiento con las cuales se ha tenido relación conceptual en tres direcciones. La primera de ellas es sociológica, la segunda es cognoscitiva y la tercera es la propia bibliotecología; en cada una de ellas se analiza cuál es el sentido con que se le ha dado al concepto, así como la red teórica en que se desenvuelve. Cabe señalar que las dimensiones analizadas son un primer acercamiento que se articulan a partir de la bibliotecología y brinda la ventaja intelectual de establecer los límites teóricos o de alcance empírico del término información, lo cual es vital para contribuir a la construcción de modelos teóricos transparentes en la disciplina bibliotecológica.

\section{DESDE LA TEORÍA DE LA INFORMACIÓN}

El sentido común nos indica que desde hace varias décadas la palabra información es un vocablo imprescindible en prácticamente todo tipo de contexto situacional o disciplinario. En el uso cotidiano es un hecho que el término es polisémico, o bien asume funciones de sinónimo de modo indiscriminado. Sin embargo, este nivel de léxico indiferenciado es el que se debe rebasar.

Comencemos por revisar la definición que ofrece el Diccionario de la lengua española (DRAE). ${ }^{1}$ Básicamente enumera ocho significados de la palabra información (en lo sucesivo I): En primer lugar se refiere a la I como acción y efecto de informar; en segundo lugar, la menciona como oficina jurídica y legal donde se informa sobre algo; en tercer lugar se le designa así a la averiguación jurídica y legal de un hecho o delito, en cuarto lugar se especifica como pruebas que se hacen de la calidad y circunstancias necesarias en una persona para un empleo u honor; en quinto lugar se le entiende como adquisición o comunicación de conocimientos que permiten ampliar o precisar los

1 Diccionario de la Real Academia Española, 22a ed., s. v. "información". 
que se poseen sobre una materia determinada; en sexto lugar se le denomina I a los conocimientos así comunicados o adquiridos; en séptimo lugar se entiende a la I como propiedad intrínseca de ciertos biopolímeros, como los ácidos nucleicos, originada por las secuencias de las unidades componentes y, en octavo lugar, se designa a la I como educación e instrucción.

Con base en las definiciones de DRAE, los diferentes contextos se circunscriben a: 1) la acción y el efecto de informar, 2) de orden orientativo y de prueba jurídica, 3) de procesos cognoscitivos y de comunicación y 4) de ámbito biológico. El DRAE también menciona la forma antigua de entender a la I como educación o instrucción.

De un modo sintético e interesante Campbell sintetizó, a principios de la década de los ochenta, los ámbitos culturales y científicos más renombrados en los cuales la I jugaba un papel destacado. Al respecto, dice lo siguiente:

¿Qué tienen en común los códigos utilizados para enviar mensajes desde una nave espacial y los genes de una molécula de ADN? ¿Cómo se relacionan la segunda ley de la termodinámica -descubierta por un físico- y la comunicación, a tal grado que sea posible hablar de la "entropía" de una partitura musical, de una página escrita, de una conversación? ¿Por qué los intricados problemas de la teoría matemática de la probabilidad se relacionan con la forma en que nos expresamos oralmente o por escrito? La respuesta a todas estas preguntas es "información", y el hecho mismo de que un solo concepto pueda ligar tantas ideas distintas revela su gran generalidad y poder. ${ }^{2}$

El mismo autor afirmó que no ha sido posible fijar el significado de I (lo cual continua siendo válido en la actualidad) y menciona que en la Edad Media tuvo varios usos populares y literarios, pero además poseía un significado más activo y constructivo, "[...] algo que da cierta forma o carácter a la materia o a la mente, una fuerza que modela la conducta, que capacita, instruye, inspira o guía". ${ }^{3}$

Campbell describe que una vez que el concepto de I fue definido científicamente en los años cuarenta, el impacto fue tal que incluso la palabra recuperó otros significados, matizando el sentido activo, como algo que "informa" al mundo material de modo semejante a los mensajes de los genes, que instruyen a la maquinaria de la célula para construir un organismo, o las señales de un transmisor de radio que guían un vehículo espacial. Así pues, además de la definición científica y sus implicaciones teóricas y tecnológicas el concepto se constituyó en un principio universal, el cual opera y "da forma 
a lo informe, especifica el carácter peculiar de las formas vivas e incluso ayuda a determinar, por medio de códigos especiales, los modelos de pensamiento humano". ${ }^{4}$ De este modo, según este autor, la I abarca los campos dispares de las computadoras de la era espacial y la física clásica, la biología molecular y la comunicación humana, la evolución del lenguaje y la del hombre.

La creación de un concepto científico de I sólo podía darse dentro de una teoría de la información, es decir, como parte de un sistema explicativo que permitiera resolver problemas de orden teórico o abstracto y de orden fenomenológico y práctico. Campbell explora dicha teoría y la propone como la entrada hacia un terreno del conocimiento tan vasto como la naturaleza y tan complejo como la mente del hombre. Destaca de modo importante que la I debe comprenderse en el marco de fuerzas complementarias que permiten explicar el mundo, esto es, la entropía como agente del caos y la I como elemento no casual "que explota la incertidumbre inherente al principio de la entropía para generar nuevas estructuras, para conformar al mundo de nuevas maneras". ${ }^{5}$ Asimismo, la idea central que expone se resume en lo siguiente:

La teoría de la información muestra que existen buenas razones para considerar que las fuerzas no accidentales son tan universales como las de la causalidad, aun cuando la entropía ha sido presentada como el principio más abrumadoramente poderoso. La metáfora apropiada para el proceso de la vida quizá no sea el tiro de un par de dados, ni girar la ruleta, sino las frases de un idioma, que llevan información parcialmente predecible y prácticamente impredecible. Estas frases se producen por reglas que obtiene mucho de poco, generando una ilimitada riqueza de significados a partir de una cantidad limitada de palabras: permiten que el lenguaje resulte familiar a pesar de ser sorprendente, y limitado a pesar de ser impredecible dentro de sus fronteras. ${ }^{6}$

De este modo, Campbell concluye a modo de afirmación universal que es posible comprender, gracias a la teoría de la información y de forma opuesta a la afirmación de la entropía (excepción y confusión como regla que gobierna el mundo), que el sentido y el orden pueden prevalecer frente al caos de manera que el orden también es completamente natural. ${ }^{7}$

Así pues, junto a los usos cotidianos de I se han propuesto conceptos distintos, aunque en ocasiones se tenga la impresión que se trata ya sea de un concepto presupuesto cuyo préstamo en otra teorías genera conceptos 
teórico-dependientes, o bien que ha logrado el estatus de un concepto metacientífico. ${ }^{8}$

\section{EN LA ERA DE LA INFORMACIÓN \\ Y LAS SOCIEDADES DEL CONOCIMIENTO}

En esta ruta intelectual el concepto de I se convirtió también en una teoría de carácter social, como un modo de observar y explicar el desarrollo de la sociedad. Esta concepción quedó fijada en la denominada Sociedad de la información. ${ }^{9}$ De igual modo, I cobró tal relevancia que Castells acuñó la expresión "la era de la información”, la cual incluye a la economía, la sociedad y la cultura. Debido a que ambas concepciones han sido tratadas con gran amplitud en la literatura especializada sólo matizaré algunos aspectos que considero relevantes.

En primer término, destaco la apreciación que se hace en el documento de la Unesco titulado Hacia las sociedades del conocimiento respecto a la concepción de Sociedad de la información, de la cual se afirma que se basa en los progresos tecnológicos. No obstante:

[...] pese a que estamos presenciando el advenimiento de una sociedad mundial de la información en la que la tecnología ha superado todas las previsiones con respecto al aumento de la cantidad de informaciones disponibles y la velocidad de su transmisión, todavía nos queda un largo camino que recorrer para acceder a auténticas sociedades del conocimiento. ${ }^{10}$

El cambio de percepción de la I al conocimiento es vital para comprender el cambio de paradigma de desarrollo social. De igual modo, se hace una fuerte crítica a la limitante que impone para las sociedades basar su progreso en la expansión de tecnologías de información y comunicación. Es así que:

8 León Olivé ha explicado que existen términos cuyos significados se construyen con relación a alguna teoría, pero esto no los excluye de aparecer en otras que dependen de la primera; en consecuencia, la segunda teoría presupone a la primera ya que esta última dota de significado pleno a los términos en cuestión. En cambio, cuando se califica un concepto de metacientífico se hace notar que es un concepto común a todas las ciencias y deben ser desarrollado en un nivel diferente del de las teorías científicas. Véase León Olivé, El bien, el mal y la razón: facetas de la ciencia y de la tecnología,México, Paidós, Universidad Nacional Autónoma de México, 2000.

9 La nota 2 del Capítulo 1 del Informe de la Unesco, titulado "De la sociedad de la información a las sociedades del conocimiento", precisa que la primera parte de la Cumbre Mundial sobre la Sociedad de la Información fue organizada por la Unión Internacional de Telecomunicaciones (UIT) y se celebró en Ginebra del 10 al 12 de diciembre de 2003. La segunda parte de dicha Cumbre quedó prevista para el año 2005. Véase: Unesco, Informe mundial de la Unesco: 
Aunque pueda "mejorarse" -por ejemplo, suprimiendo las interferencias o errores de transmisión- una información no crea forzosamente sentido. Además, la información sólo seguirá siendo una masa de datos indiferenciados hasta que todos los habitantes del mundo no gocen de una igualdad de oportunidades en el ámbito de la educación para tratar a la información disponible con discernimiento y espíritu crítico, analizarla, seleccionar sus distintos elementos e incorporar los que estimen más interesantes a una base de conocimientos. Muchos se darán cuenta de que en lugar de dominar la información, es ésta la que los domina a ellos. Además el exceso de información no es forzosamente una fuente de mayor conocimiento. Es necesario que los instrumentos que permitan tratar la información estén a la altura. ${ }^{11}$

El documento de la Unesco establece de modo contundente que estas concepciones de sociedad no deben confundirse. En todo caso, el nacimiento de la Sociedad de la información basada en la revolución de las nuevas tecnologías es tan sólo un instrumento para alcanzar el modelo de sociedades del conocimiento. Lo anterior también implica diferenciar entre el uso del concepto de I respecto al de conocimiento, ya que "La información es efectivamente un instrumento del conocimiento, pero no es el conocimiento en sî". ${ }^{12}$ Ahora bien, la dimensión social es importante para distinguir una concepción de sociedad más justa, ya que:

La información es en potencia una mercancía que se compra y vende en un mercado y cuya economía se basa en la rareza, mientras que un conocimiento -pese a determinadas limitaciones: secreto de Estado y formas tradicionales de conocimientos esotéricos, por ejemplo- pertenece legítimamente a cualquier mente razonable, sin que ello contradiga la necesidad de proteger la propiedad intelectual. La excesiva importancia concedida a las informaciones con respecto a los conocimientos pone de manifiesto hasta qué punto nuestra relación con el saber se ha visto considerablemente modificada por la difusión de los modelos de economía del conocimiento. ${ }^{13}$

Un componente que impulsó la difusión del concepto de Sociedad de la información fue la promesa implícita respecto a la posibilidad de arribar a escenarios de desarrollo social benéficos con base en el salto tecnológico y el inmenso potencial que brindan. En esta línea de análisis, Manuel Castells expuso hacia 1996 que la revolución tecnológica centrada en las tecnologías de la información estaba modificando aceleradamente la base material de la sociedad y destacó que se trataba del advenimiento de "la era de la

11 Ibid., p. 20. Las cursivas son mías.

12 Ibid., p. 10.

13 Ibid., p. 19. 
información". ${ }^{14}$ De modo específico, Castells propone el concepto de sociedad informacional y global y, sobre la base de una perspectiva de paradigma tecnoeconómico o sociotécnico, subraya que durante las dos décadas finales del siglo XX se llevó a cabo la Revolución de la tecnología de la información. Para entender cómo florecen las nuevas tecnologías de la información dicho autor considera esenciales diversos factores: en principio advierte sobre el rol de los programas de macroinvestigación en los Estados Unidos y los extensos mercados desarrollados por el Estado; también alude a la innovación descentralizada por una cultura de creatividad tecnológica y modelos de rápido éxito personal, de tal modo que "agruparon a su alrededor redes de empresas, organizaciones e instituciones para formar un nuevo paradigma sociotécnico". ${ }^{15}$

Vale la pena traer a colación las consideraciones del autor respecto a la transformación tecnológica que ha tenido lugar en la sociedad. Desde los años noventa ha surgido un nuevo paradigma epistemológico compartido por científicos e investigadores, opuesto a la "teoría del caos" a la cual se refería también Campbell. ${ }^{16}$ Este nuevo planteamiento fue identificado con el término complejidad y está centrado en la comprensión del surgimiento de estructuras auto organizadoras que crean complejidad de la simplicidad " $y$ un orden superior del caos por medio de diversos órdenes de interactividad de los electos básicos que se encuentran en el origen del proceso". ${ }^{17}$

Añade que el pensamiento sobre la complejidad debe considerarse un método para comprender la diversidad en lugar de una metateoría unificada, y advierte que su valor epistemológico proviene del reconocimiento del don de la naturaleza y la sociedad para descubrir cosas sin proponérselo; por supuesto, no se trabaja sin reglas "sino que las reglas son creadas, y cambiadas, en un proceso constante de acciones deliberadas e interacciones únicas. ${ }^{18}$

En un lenguaje que recuerda a Luhmann, ${ }^{19}$ Castells afirma que el paradigma de la tecnología de la información no evoluciona hacia su cierre como sistema, sino hacia su apertura como una red multifacética. Califica dicho paradigma de poderoso e imponente en su materialidad, pero es adaptable y abierto en su desarrollo histórico, de tal modo que sus cualidades radican en su carácter integrador, la complejidad y la interconexión.

14 La obra monumental que publicó Castells en tres volúmenes a mediados de los noventa lleva por título La era de la información: economía, sociedad y cultura. El primer volumen trata la sociedad red, el segundo aborda el tema del poder de la identidad y el tercero analiza el fin de milenio.

15 Manuel Castells, La era de la información: economía, sociedad y cultura, p. 87.

16 Campbell, op. cit.

17 Castells, op. cit., p. 91.

18 Idem. res Navarrete. 
Contrario a lo afirmado por Campbell, Castells se refiere a la I de modo más objetivo y sin pretensión de convertirla en principio universal, e indica que la I y el conocimiento siempre han sido componentes cruciales del crecimiento económico. Para este autor la evolución de la tecnología ha determinado la capacidad productiva de la sociedad y los niveles de vida, así como las formas sociales de la organización económica. Además, menciona que:

El surgimiento de un nuevo paradigma tecnológico, organizado en torno a nuevas tecnologías de la información más potentes y flexibles, hace posible que la misma información se convierta en el producto del proceso de producción. Para ser más precisos, los productos de las nuevas industrias de las tecnologías de la información son aparatos para procesar la información o el mismo procesamiento de la información. $^{20}$

Tomando en cuenta lo anterior, al transformar los procesos del procesamiento de la información las nuevas tecnologías de la información intervienen en todos los dominios de la actividad humana y establecen conexiones infinitas entre los diferentes dominios, agentes y elementos de dichas actividades. ${ }^{21}$

Una de las ideas centrales que aporta Castells para entender mejor la revolución tecnológica consiste en caracterizar la aplicación del conocimiento y de la I a aparatos de generación de conocimiento y "procesamiento de información/comunicación” que retroalimentan acumulativamente la innovación y sus usos. En consecuencia, lo distintivo no es el conocimiento y la I como tales, sino su aplicación en los términos antes indicados. Por otra parte, resume el Paradigma de la Tecnología de la Información en cinco características:

1. La I es su materia prima y son tecnologías para actuar sobre la misma I.

2. La capacidad de penetración de los efectos de las nuevas tecnologías. Este nuevo medio tecnológico es capaz de modelar todo el proceso de la existencia individual y colectiva, aunque no los determine.

3. La interconexión de todo sistema o conjunto de relaciones que hacen uso de estas tecnologías, por tanto, la morfología de red está mejor adaptada "para una complejidad de interacción creciente y para pautas de desarrollo impredecibles que surgen del poder creativo de esa interacción". ${ }^{22}$

20 Castells, op. cit., p. 94.

21 Idem.

22 Ibid., p. 88. 
4. La flexibilidad y capacidad de reconfiguración, sin destruir una organización, ya que la base material de dicha organización puede reprogramarse y reequiparse.

5. Convergencia creciente de tecnologías específicas en un sistema altamente integrado, de lo cual resulta que las antiguas trayectorias tecnológicas separadas se vuelven indistinguibles.

Castells establece al final del primer volumen de La era de información que, si la revolución tecnológica a la cual está asociada la I y el conocimiento se analiza en términos sociológicos, la sociedad red representa un cambio cualitativo en la experiencia humana, tomando el referente de la acción social como el modelo cambiante de las relaciones entre naturaleza y cultura. Ahora bien, sobre la base de esta premisa indica que han existido tres modelos: el primero se caracterizó por el dominio de la naturaleza sobre la cultura; el segundo surgió en los orígenes de la Edad Moderna, asociado con la Revolución Industrial y el triunfo de la razón, lo cual permitió el dominio de la naturaleza por la cultura. El tercer modelo se distingue porque "la cultura hace referencia directa a la cultura", esto es, una vez dominada la naturaleza ésta se revive o preserva de modo artificial como una forma cultural..$^{23}$

Una de sus conclusiones vinculada estrechamente a la I es la siguiente:

Debido a la convergencia de la evolución histórica y el cambio tecnológico, hemos entrado en un modelo puramente cultural de interacción y organización sociales. Por ello, la información es el ingrediente clave de nuestra organización social, y los flujos de mensajes e imágenes de unas redes a otras constituyen la fibra básica de nuestra cultura social. [...] Es el comienzo de una nueva existencia y, en efecto, de una nueva era, la de la información, marcada por la autonomía de la cultura frente a las bases materiales de nuestra existencia. Pero no es necesariamente un momento de regocijo porque, solos al fin en nuestro mundo humano, habremos de mirarnos en el espejo de la realidad histórica. ${ }^{24}$

Por otra parte, Castells sintetiza el sentido esencial que encierra la era de la información en el "Finale" del tercer volumen de su obra:

La promesa de la era de la información es la liberación de una capacidad productiva sin precedentes por el poder de la mente. Pienso, luego produzco. Al hacerlo tendremos tiempo libre para experimentar con la espiritualidad y la posibilidad de reconciliarnos con la naturaleza, sin sacrificar el bienestar material de nuestros hijos. El sueño de la Ilustración, que la razón y la ciencia resolvieran los problemas 
de la humanidad, está a nuestro alcance. No obstante, existe una brecha extraordinaria entre nuestro sobredesarrollo tecnológico y nuestro subdesarrollo social. ${ }^{25}$

En esta reflexión final Castells se acerca bastante a los postulados y problemas respecto a la justicia y el conocimiento de la Unesco, ${ }^{26}$ así como a los planteamientos de Nussbaum ${ }^{27}$ y Sen, ${ }^{28}$ además de los Informes para el Desarrollo Humano del Programa para el Desarrollo Humano de las Naciones Unidas (PNUD). ${ }^{29}$

La obra La era de la información es imprescindible para entender la revolución tecnológica acontecida en las últimas décadas, pero particularmente es fundamental para los estudiosos de la disciplina bibliotecológica, ya que los actores centrales de este cambio de era involucran directamente a la I, al conocimiento y a las tecnologías de la información. Lo identifica, como ya fue expuesto, con el nombre de modelo de desarrollo informacional. Se reitera que en dicho modelo la fuente de productividad estriba en dos procesos interdependientes: la tecnología de generación del conocimiento, por un lado, y el procesamiento de la I y símbolos por otro.

El modelo informacional se caracteriza por la acción del conocimiento sobre sí mismo como fuente de productividad. En cuanto al procesamiento de la I, se centra en la superación de la tecnología de dicho procesamiento. En resumen, el modelo se refiere a la interacción de las fuentes del conocimiento de la tecnología y la aplicación de ésta para mejorar la generación de conocimiento y el procesamiento de la información. ${ }^{30}$ Por consiguiente, el trabajo de la disciplina bibliotecológica está enriqueciendo este modelo de desarrollo informacional como coadyuvante de la acción del conocimiento sobre sí mismo y en el procesamiento de la información y la comunicación de símbolos.

Llama la atención en la obra de Castells que utilice sólo una nota para aclarar qué entiende por información y conocimiento, ${ }^{31}$ en tanto que ambos conceptos son esenciales para clarificar el modelo de desarrollo informacional. Así pues, es pertinente recuperar las definiciones que utiliza. Castells

25 Ibid., p. 394. Las cursivas son mías.

26 Véase Unesco, op. cit.

27 Véase Martha C. Nussbaum, Crear capacidades: propuesta para el desarrollo bumano, Madrid, Paidós, 2012

28 Véase Amartya Sen, La idea de la justicia, México, Taurus, 2010.

29 Los Informes de Desarrollo Humano están disponibles en http://www.undp.org/content/un $\mathrm{dp} / \mathrm{es} /$ home/librarypage.html

30 Castells, op. cit., p. 43.

31 Ibid., nota 27 del vol. I; véase también Daniel Bell, El advenimiento de la sociedad posindustrial, Madrid, Alianza, 1975, y Marc Porat, The information economy: definition, and measurement, Washington D. C., Oficina de Telecomunicaciones Washington D. C., 1977. 
recurre a Daniel Bell, quien define el conocimiento como una serie de afirmaciones organizadas de hechos o ideas que presentan un juicio razonado o un resultado experimental que se transmite a los demás mediante algún medio de comunicación en alguna forma sistemática. En cuanto a la definición de I se cita a Porat: "La información son los datos que se han organizado y comunicado". ${ }^{32}$

Por su parte, en la nota 4 de la Introducción ${ }^{33}$ el Informe de la Unesco utiliza las definiciones de los conceptos empleados por Castells. Sin embargo, su uso se inserta en contextos intelectuales totalmente distintos, pues en el caso del modelo informacional ambos conceptos están articulados a una teoría que explica el advenimiento de la era de la información centrado en la productividad; en cambio, en la perspectiva de la Unesco respecto a las sociedades del conocimiento los conceptos ya mencionados están integrados a una teoría normativa cuyas bases filosóficas y políticas provienen de la teoría política de la justicia y las capacidades, expuesta ampliamente por Sen, Nussbaum y los Informes del Desarrollo Humano del PNUD.

Asimismo, vale la pena destacar que la Unesco, además de enfatizar el concepto conocimiento, de ninguna manera rechaza los postulados y afirmaciones establecidas en la perspectiva del modelo informacional, antes bien considera que dicho modelo es el preámbulo para arribar a una sociedad más justa, de tal modo que la productividad económica y científica quede centrada en el desarrollo humano de las sociedades. El modelo informacional adquiere así un carácter instrumental.

Por lo anterior, el auge de las nuevas tecnologías de la información y la comunicación ha creado nuevas condiciones para la aparición de sociedades del conocimiento, y agrega que:

La sociedad mundial de la información en gestación sólo cobrará su verdadero sentido si se convierte en un medio al servicio de un fin más elevado y deseable: la construcción a nivel mundial de sociedades del conocimiento que sean fuentes de desarrollo para todos, y sobre todo para los países menos adelantados. Para lograrlo, dos desafíos planteados por la revolución de la información revisten una importancia particular: el acceso a la información para todos y el futuro de la libertad de expresión. ${ }^{34}$

Asimismo, en opinión de la Unesco, un elemento central de las sociedades del conocimiento es la capacidad para identificar, producir, tratar, transformar, difundir y utilizar la información con vistas a crear y aplicar los 
conocimientos necesarios para el desarrollo humano. Menciona también que estas sociedades "se basan en una visión de la sociedad que propicia la autonomía y engloba las nociones de pluralidad, integración, solidaridad y participación".35

La crítica de la Unesco se dirige a las consecuencias de la tercera revolución industrial, es decir, las nuevas tecnologías y la nueva fase de mundialización que la acompaña, ya que:

[...] han modificado radicalmente numerosos puntos de referencia y aumentado las brechas existentes entre ricos y pobres, entre países industrializados y países en desarrollo, e incluso entre los ciudadanos de un mismo país. La Unesco estima que la edificación de las sociedades del conocimiento es la que "abre camino a la humanización del proceso de mundialización” ${ }^{36}$

Es importante insistir que el cambio de paradigma teórico propuesto en la era de la información respecto a las sociedades del conocimiento persigue objetivos epistémicos diferentes. El primero de estos paradigmas es descriptivo y explicativo, mientras que el segundo es normativo, es decir, posee un carácter orientativo. Esto es importante ya que varios problemas señalados en el documento de la Unesco también fueron abordados en la obra de Castells; sin embargo, el tratamiento diferenciado en uno y otro paradigma obedece a argumentaciones que persiguen fines distintos. Así, respecto a la era de la información se incluye en las conclusiones la información siguiente: "El siglo XXI no será una era tenebrosa, pero tampoco procurará a la mayoría de la gente las prodigalidades prometidas por la más extraordinaria revolución tecnológica de la historia. Más bien, se caracterizará por una perplejidad informada" ${ }^{37}$

En cuanto a las sociedades del conocimiento se concluye con orientaciones y recomendaciones del siguiente tipo:

Ante estos desafíos la comunidad internacional -ya se trate de gobiernos y organizaciones internacionales, tanto gubernamentales y no gubernamentales, como del sector privado- deberían dar prioridad a tres iniciativas que constituirían otros tantos pilares sobre los que podrían edificarse auténticas sociedades del conocimiento para todos:

- Una mejor valorización de los conocimientos existentes para luchar contra la brecha cognitiva;

36 Idem

37 Castells, op. cit.,p. 392. 


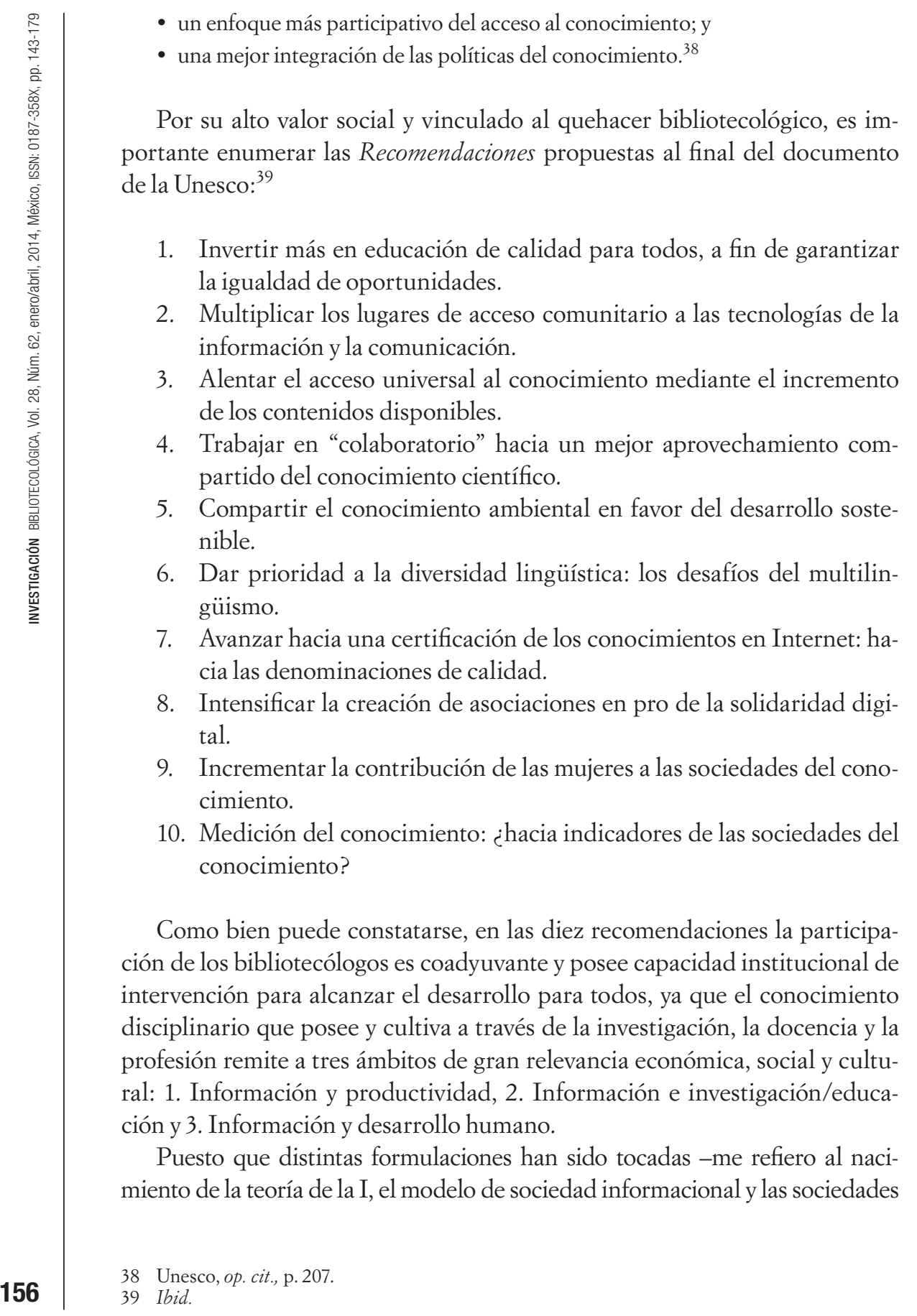


del conocimiento- que ellas han brindado modelos de observación general de la sociedad ${ }^{40}$ y en cada una de estas el concepto de I invariablemente está asociado al concepto de conocimiento, ya sea como antecedente o como consecuente; en paralelo, también se incluye el concepto de tecnologías de la información y tecnologías del conocimiento.

Sin embargo, la conseja metodológica consiste en acotar el marco teórico desde el cual se utilizan los conceptos antes señalados, ya que el uso indiscriminado de ellos los ha llevado a extremos de banalización, de tal modo que sin el referente teórico del concepto es inevitable hacer afirmaciones falsas o superfluas. En este punto, Moulines refiere que las disciplinas científicas tienen como una de sus características el uso de un vocabulario específico, "de ciertas palabras y expresiones que no son del acervo común de los lenguajes comúnmente hablados, sino que son introducidas especialmente en un contexto científico. El sentido de tales términos, no puede ser apresado plenamente si no se tiene un conocimiento mínimo de la disciplina en la que aparecen" ${ }^{41}$ A continuación este mismo autor, asevera que lo esencial en los términos a los que nos referimos "no es pues que tengan un origen científico, sino que su uso sólo puede estar sancionado por una teoría científica, y que sólo quien conozca bien esta teoría, podrá hacer un uso genuino de ellos". ${ }^{4}$

En cuanto a los términos que nos ocupan, sería conveniente precisar cuándo nos referimos a I o a conocimiento, como "término teórico", o bien, como "concepto teórico". Por ejemplo, en la teoría de la información de Shannon, en realidad se tiene un "término teórico" al redefinir I. ${ }^{43}$ En cambio, tanto en Castells como en documento de Unesco aquí mencionado, se está frente a "conceptos teóricos". La diferencia entre éstos es que el primero de ellos es una entidad lingüística que aparece en la formulación canónica de una teórica; en el otro caso se trata de una expresión más general y no presenta una formulación más específica. ${ }^{44}$

Con base en las precisiones anteriores y respecto a la pregunta ¿qué tipo de concepto es "información"? Es posible responder que dependiendo de la teoría que lo utilice es posible observar tres usos:

1. La información como concepto métrico o de magnitud

2. La información como idealización; y

3. La información como término con referente real, pero inobservable en principio.

40 Este concepto lo he tomado de René Millán, Complejidad social y nuevo orden en la sociedad mexicana, México, UNAM, IIS, Miguel Angel Porrúa, 2008.

41 Ulises Moulines, "Conceptos teóricos y teorías científicas", p. 147.

42 Ibid., p. 148.

43 Véase Campbell, op. cit.

44 Esta distinción es presentada por Moulines en el trabajo antes citado. 
En el primer caso, se trata de la aportación fundamental de Shannon, quien

[...] escogió como su unidad de información el digito binario o bit. Un bit es una medida de cantidad de información, así como un galón, una onza u una pulgada miden volumen, peso y longitud. Un bit es sólo un elección entre dos mensajes igualmente probables. Es una respuesta de "si" o "no" a la pregunta hipotética: ¿"Es éste?" La respuesta "sî" resuelve toda incertidumbre en la mente de la persona que recibe el mensaje, porque sabe cuál de los dos posibles mensajes es el real. La respuesta "no" también resuelve su incertidumbre, porque sabe que el mensaje real no es la primera alternativa sino la segunda. ${ }^{45}$

De acuerdo con Campbell, la información se convirtió en un concepto científico cuando iniciaba la era de la comunicación electrónica, en la primera parte del siglo XX y, los científicos en gran medida lo que sus predecesores del siglo XIX habían hecho con el concepto de energía: "Lo convirtieron en teoría, le dieron leyes, lo festonaron con ecuaciones y, como acostumbran, lo despojaron, en la medida de lo posible, de vaguedad y misterio". ${ }^{46}$

El impacto de la teoría de la información, no únicamente del concepto, es tal que según el autor antes citado la naturaleza ya no se puede considerar tan sólo como materia y energía y tampoco pueden descubrirse sus secretos con:

[...] las llaves de la química y la física, por más que estas dos ramas científicas hayan tenido éxito deslumbrante en nuestro siglo. Para toda explicación del mundo que pretenda ser completa, resulta indispensable un tercer componente. A las poderosas teorías de la química y la física debe añadirse una recién llegada: una teoría de la información. La naturaleza tiene que ser interpretada como materia, energía e información. ${ }^{47}$

En su momento, la teoría de la información respondió preocupaciones medulares de diferentes campos disciplinarios, expresadas en términos de: ¿Cómo es posible el orden y el desorden? ¿Cómo es posible el error y el control del error? ¿Qué papel juegan las posibilidades y la realización de posibilidades? ¿Qué es la incertidumbre y cuáles son sus límites?

De modo transparente, y para dar realce a la teoría de la información Campbell expresa lo siguiente:

Los científicos todavía se preguntan por qué los productos de la naturaleza resultan tan improbables, por qué manifiestan tanto orden cuando su 
estado más probable sería la confusión y el error, una rendición a las fuerzas del desorden universal que parecen tan abrumadoras y naturales. Esto aún se considera como una de las preocupantes paradojas de la ciencia, y es prima hermana de la eterna pregunta de la filosofía: "Por qué existe algo en lugar de la nada? En sus ensayos de 1948, Shannon probó que, contrariamente a lo que pudiera esperarse, "algo", un mensaje, puede persistir en medio de la "nada", de un desorden azaroso o un ruido. ${ }^{48}$

Ya cumplió más de cinco décadas la teoría de la información y su impacto fue tal que se convirtió en teoría premisa para apoyar las explicaciones de otras disciplinas de carácter social, como por ejemplo, la pedagogía, las ciencias de la comunicación e inclusive la bibliotecología. Actualmente se trata de un vasto campo de estudio, con interés predominante para la bibliotecología, la sociología, la lingüística y las ciencias cognitivas, por mencionar sólo algunas.

En relación con el segundo caso de la información como concepto ficcional, cabe reiterar que se trata de términos utilizados en las disciplinas con fuerte tendencia a la matematización y se llega afirmar que son conceptos que ninguna entidad real cae bajo ellos. Ahora bien, según Moulines, no se trata de términos puramente matemáticos, pues,

[...] por el contrario, aunque su referente es vacío, van asociados como "idealizaciones" o "aproximaciones" a entidades reales; por ejemplo, a partículas reales, máquinas reales, gases reales, gases reales o seres humanos de carne y hueso. Por otro lado, sería erróneo considerarlos como términos superfluos. Muchas veces (como en los ejemplos considerados), la teoría a la que pertenecen, y que es una buena teoría empírica, no sería ni siquiera formulable sin ellos. ${ }^{49}$

De acuerdo con esta explicación, y con base en el análisis hasta ahora realizado, tanto en la disciplina bibliotecológica, como en otras más, el concepto de información se utiliza como idealización o aproximación a entidades reales.

Como ejemplo de lo anterior consideremos el uso que hace Bateson y Luhmann. ${ }^{50}$ El primero de ellos desarrolló una visión interdisciplinaria (epistemología, lingüística, biología) y el segundo lo trabajó en el campo de la sociología; cabe indicar que ambos hicieron aportaciones intelectuales sumamente relevantes.

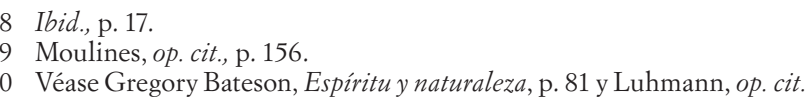




\section{INFORMACIÓN Y DIFERENCIA}

Bateson en sus estudios se plantea la siguiente pregunta: “¿Qué agregado o incremento del saber se deriva de una combinación de información procedente de dos fuentes?" ${ }^{51}$ Este autor señala que su interés se dirige a las variedades de información que brindan al organismo perceptor información sobre el mundo que lo rodea o sobre sí mismo como parte del mundo externo. ${ }^{52}$ Es decir, cómo se incrementa el conocimiento a partir de la combinación de fuentes de información.

Es necesario señalar que Bateson es reconocido mundialmente por haber señalado que la información o la unidad elemental de información es la diferencia que hace la diferencia. ${ }^{53}$ Es muy importante recalcar que esta última definición de información es la que empleó Luhmann para exponer y desarrollar su teoría de sistemas en el campo de la sociología. ${ }^{54}$ Así pues, Bateson indica que para crear una diferencia se necesita como mínimo dos entidades y explica que:

Para producir información, vale decir, noticias acerca de una diferencia, debe haber dos entidades (reales o imaginarias) tales que la diferencia entre ambas pueda ser inmanente a su relación mutua; y toda la cuestión debe ser de tal índole que las noticias acerca de su diferencia puedan representarse como una diferencia inherente a cierta entidad procesadora de información, como un cerebro o, tal vez, una computadora. ${ }^{55}$

El propio autor observa que existe una honda interrogante sin respuesta acerca de la naturaleza de esas cosas, pues "como mínimo dos", que generan entre ellas la diferencia que se torna información por ser una diferencia. Este es el punto focal de su planteamiento y, aunque complejo, cada una de ellas por sí sola es una no-entidad "una no-ser. No diferente del ser y no diferente del no-ser. Algo inconcebible, una Ding an sich, el sonido de una sola mano que aplaude". 56

Para precisar la comprensión acerca del incremento de conocimiento como producto de la información, Bateson anota que cualquier objeto, suceso o

51 Bateson, op. cit., p. 80.

52 Idem.

53 Luciano Floridi señala que MacCrimmon MacKay escribió el siguiente enunciado: "la información es una distinción que hace la diferencia”; asimismo comenta que Bateson reformuló el enunciado de modo menos preciso cuando indica: "la información -la unidad elemental de información- es una diferencia la cual hace una diferencia”. Véase Floridi, Information: a very short introduction.

54 Luhmann, op. cit., p. 63. 
diferencia en el mundo externo puede convertirse en fuente de información, siempre y cuando sea incorporado a un circuito con una red apropiada de material flexible en el que sea capaz de producir cambios. Lo consideración anterior, la amplía del siguiente modo:

Pasamos así al enunciado más amplio posible de la famosa generalización de Korzybski: el mapa no es el territorio. Viendo las cosas con la vasta perspectiva que ahora tenemos, el mapa es para nosotros una suerte de efecto que suma diferencias, que organiza noticias sobre las diferencias en el "territorio". El mapa de Korzybski es una metáfora conveniente y ha sido útil a mucha gente, pero reducida a su más extrema simplicidad, su generalización afirma que el efecto no es la causa. ${ }^{57}$

Los planteamientos anteriores aclaran suficientemente cómo se produce el incremento de conocimiento a partir de la información (la diferencia en la diferencia) y resalta la necesidad de contar con una red flexible capaz de producir cambios. De este modo tenemos que el concepto "información" es una idealización que representa las diferencias que importan en los planos epistémicos o cognoscitivos de los sujetos.

Por otra parte, Luhmann, además de retomar el concepto de información (la diferencia que bace la diferencia), incorpora un contexto explicativo basado en la comunicación en el cual se articula el sentido y función del concepto información.

$\mathrm{Al}$ respecto, Rodríguez $\mathrm{M}^{58}$ explica que con el cambio fundamental introducido por Luhmann se tiene una innovación conceptual dentro de la sociología, ya que la perspectiva de Parsons basada en la acción social dominó buena parte del ambiente académico del siglo XX. Agrega que esta reconceptualización es importante ya que solamente la comunicación es siempre un fenómeno social, a diferencia de la acción que es genéricamente individual y requiere ser calificada de social. Sin embargo:

La comunicación no consiste en una transmisión de alguien a alguien, como pretende la persistente teoría de la acción, sino la síntesis de tres selecciones que tiene lugar en la presencia de alter y ego, pero que no consiste de las acciones de éstos. La comunicación, por tanto, es un fenómeno emergente que caracteriza el paso del nivel psicológico individual al nivel social en que los individuos quedan formando parte esencial del entorno. ${ }^{59}$

7 Ibid., p. 123.

58 Niklas Luhmann, Organización y decisión.

59 Ibid., p. 14. 
Asimismo, Rodríguez destaca que para Luhmann existe un trabajo continuo de selección asociado a la información y lo sintetiza del siguiente modo:

Las tres selecciones cuya síntesis configura la comunicación son:

a) Selección de una información. Alter debe seleccionar entre las informaciones de que dispone cuál es la que desea compartir con Ego. Información es entendida por Luhmann, de acuerdo a la definición de Bateson, como "la diferencia que hace la diferencia”. Por esta razón, la información siempre sorprende y sólo es información al momento de ser recibida, en el instante en que "hace la diferencia” con lo que Ego sabía: no antes, porque no la conoce, tampoco después, porque ya la sabe.

b) Selección de un modo de darla-a-conocer la información seleccionada. Además, escoge las palabras y gestos con que la ha de expresar.

c) Selección de una comprensión. Ego selecciona lo que entiende de lo que ha escuchado o leído. Trata de dilucidar cuál es la información portada por el modo de darla-a-conocer que ha recibido de parte de Alter. ${ }^{60}$

Asimismo, se aclara que la comunicación, no son en lo particular las selecciones sino su síntesis y que en ello radica su carácter social, además, "sólo se produce en el momento en que Ego selecciona la comprensión, lo que, naturalmente, incluye la incomprensión". ${ }^{61}$

A continuación revisemos lo que el propio Luhmann ${ }^{62}$ ha escrito respecto a la información y la selección. Este autor comienza por aclarar que desde la década de los cincuenta se da el auge en el empleo del concepto de información, pero sin alcanzar claridad conceptual. Por ejemplo, cuando se menciona la información genética, se trata a las estructuras como contenidos de información. También explica que la pregunta relevante sobre el concepto de información es: ¿cuál es la escala en la que la información puede seleccionar? En consecuencia, se está frente a un concepto que presenta dos formas:

1. La información es un concepto que se dirige a lo que todavía no ha sido procesado en el sistema.

2. Se deslinda de lo que ya ha sido elaborado o sobre lo que se trabaja permanentemente.

Por ello, expone Luhmann, se denomina información a un acontecimiento que selecciona estados del sistema; para ello se requiere estructuras que 
limitan y preseleccionan las posibilidades, de tal modo que la información presupone estructura, pero no es en sí misma ninguna estructura. Más bien, se trata de un acontecimiento que actualiza el uso de las estructuras, ya que los acontecimientos son elementos que se fijan puntualmente en el tiempo, acontecen una sola vez y sólo en el lapso mínimo necesario para su aparición. En consecuencia:

Este suceder temporal los identifica y, por lo tanto, son irrepetibles. Precisamente por esto sirven como elementos de unidad de los proceso. Esto se comprueba, justamente, por medio de la información. Una información cuyo carácter de sorpresa se repita ya no es información; conserva su sentido en la repetición, pero pierde el valor de información. La Universidad, el que todavía esté allí y se mantenga, ya no reviste valor de información (ya no cambia el estado del sistema, aunque presente estructuralmente la misma selección). Por otro lado, no se pierde la información, aunque haya desaparecido como acontecimiento. Cambió el estado del sistema y dejó con ello un efecto de estructura: el sistema reacciona ante estas estructuras cambiadas y cambia con ellas. La información es, por lo tanto, siempre información de un sistema. ${ }^{63}$

Este autor menciona las siguientes características asociadas a la información:

a) Para que la información tenga el valor de la función articulada a los estados de sistema, debe tratarse de sistemas autopoiéticos, es decir, de sistemas que siempre actúan en la transformación de su propio estado.

b) La información reduce complejidad en la medida en que da a conocer una selección y, en consecuencia, excluye posibilidades. Puede aumentar, no obstante, la complejidad.

c) La información posee también dos rasgos. Por una parte, en cuanto al carácter de sorpresa y, por la otra, si la sorpresa está presupuesta en el sistema de expectativas.

Luhmann afirma que:

La información no es la exteriorización de una unidad, sino la selección de una diferencia que lleva a que el sistema cambie de estado y que, por consiguiente, se opere en él otra diferencia. Tomado todo esto en conjunto conduce a la consideración de que la información sólo es posible en el sistema. Cada sistema produce su 
información ya que cada sistema construye sus propias expectativas y esquemas de ordenamiento. ${ }^{64}$

En resumen, Luhmann considera que la información es un estado que surge desde dentro del sistema y, por las razones antes expuestas, no fuera de él.

Un ejemplo interesante para analizar problemas bibliotecológicos, particularmente de bibliometría, con base en la teoría de sistemas de Luhmann, lo presenta Vélez. ${ }^{65}$ El estudio que realizó incluye el siguiente marco conceptual basado en la comunicación y la información como diferencia, aunque también incluye la expresión la información con sentido.

En primer lugar parte de la premisa: un acontecimiento comunicativo es la aparición de una distinción con forma de marca. En segundo lugar se establece que una marca (como distinción de información) es posible porque existen otras marcas con las que se enlaza y esto posibilita la comunicación "por ejemplo, en una conversación, los temas recurrentes, así sean nuevos para los interlocutores, participan de la conversación están persuadidos de ello a través de la experiencia con la información involucrada, sus formas de expresarla y entenderla”. ${ }^{66}$

Como tercer punto, Vélez explica como para el caso de la ciencia, las marcas poseen la particularidad especial que integra la forma de la comunicación científica. En tal caso, un artículo científico se le identifica como un evento de comunicación. Ahora bien, este evento presenta marcas específicas que le dan forma y han sido estandarizadas. Los sistemas de indización, han permitido estandarizar tales marcas de identificación de un texto científico y algunas de ellas son:

Que el texto haga parte de una revista arbitrada e indizada en sistemas de prestigio (por ejemplo: SSCI, SCI, Scopus, como las más importantes a nivel global).

Que el texto tenga una estructura adecuada y ya formalizada por las publicaciones que están o aspiran a pertenecer a estos sistemas de indización. Título, palabras claves, resúmenes (en varios idiomas), referencias actuales, claridad en el campo especializado desde el cual se escribe y una estructura formal cercana a: problematización, teorías, metodologías, discusión y conclusiones. ${ }^{67}$

De acuerdo con este autor, las marcas se expresan a través de palabras y la inclusión de estas palabras en presencia de otras más la repetición o variación de las combinaciones de éstas, posibilitan especificar el sentido de

64 Ibid., p. 106.

65 G. Vélez Cuartas, "Las redes de sentido como modelo para la conservación de la ciencia: Luhmann desde un punto de vista estructural". 
los textos. Por ello la comunicación científica adquiere sentido en la misma redundancia de palabras, las cuales en distintas combinaciones indican, por ejemplo: autores prestigiosos, por su aparición continua en distintos textos; la formación de conceptos, a partir de las distintas combinaciones de términos que tienen éxito durante cierto tiempo dentro de los distintos campos; y la conformación de especialidades, por la tematización recurrente y las distintas combinaciones utilizadas por los textos en sus propias referencias bibliográficas adscritas a diferentes campos científicos. ${ }^{68}$

El siguiente abordaje que se ha hecho sobre el concepto de información idealización o aproximación a entidades reales, es resumido por Floridi. ${ }^{69}$ Este autor define a la información con base en los datos. Sin embargo, la información como datos, posee un conjunto de atributos que es necesario desglosar, sobre todo, porque esta definición se ha utilizado frecuentemente en la bibliotecología y las disciplinas afines.

Floridi comienza por señalar que existe una General Definition of Information, por sus siglas GDI, compuesta por datos + significado; también agrega que esta definición es de uso frecuente en los campos que tratan la los datos y la información como entidades materializadas o con referente real. La definición se integra de tres apartados, cuya organización lógica es la siguiente:

Table 1. The General Definition of Information (GDI)

GDI) $\sigma$ is an instance of information, understood as semantic content, if and only if:

GDI.1) $\sigma$ consists of $n$ data, for $n>1$;

GDI.2) the data are well formed;

GDI.3) the well-formed data are meaningful. ${ }^{70}$

\section{INFORMACIÓN Y DATOS}

Es así que la información se compone de datos y significado, lo cual implica un circuito que abarca diferentes actores y componentes: a) la organización de los datos, b) las reglas (sintaxis) que gobiernan el sistema elegido y c) significados convenidos y válidos dentro del sistema elegido.

68 Ibid., p. 232.

69 Floridi, op. cit.

70 Ibid.p. 21.

Definición General de Información (GDI)

GDI) $\sigma$ es un ejemplo de información, entendido como contenido semántico, si y sólo si:

GD I1) $\sigma$ se compone de $n$ datos, donde $n>1$;

GD I2) los datos están bien estructurados;

GD I3) los datos que están bien estructurados, son significativos. 
Dado que el énfasis está dado en el término dato, Floridi presenta la siguiente definición ${ }^{71}$ :

Dd) datum $=_{\text {def. }} x$ being distinct from $y$, where $x$ and $y$ are two uninterpreted variables and the relation of 'being distinct', as well as the domain, are left open to further interpretation. ${ }^{72}$

Al respecto Floridi afirma que la definición anterior puede aplicarse de tres maneras:

1. Los datos pueden carecer de uniformidad en el mundo real.

2. Los datos pueden carecer de uniformidad (su percepción) entre dos estados físicos de un sistema o señales.

3. Los datos pueden carecer de uniformidad entre dos símbolos. ${ }^{73}$

Asimismo, Floridi propone la siguiente tipología de datos:

Datos primarios. Datos almacenados dentro de bases de datos relacionales. Es decir, son los datos de un sistema de gestión de información.

Datos secundarios. Estos son contrarios a los datos primarios, cuando estos últimos están ausentes.

Metadatos. Son indicaciones sobre la naturaleza de otros datos (usualmente sobre los datos primarios).

Datos operativos. Datos relacionados con las operaciones de un sistema de datos en su conjunto y su desempeño.

Datos derivados. Pueden extraerse de otros datos, siempre que se usen como fuentes indirectas en busca de patrones, pistas o evidencias que infieran sobre los datos en sí mismos. ${ }^{74}$

Al revisar otras definiciones elaboradas con anterioridad, no se aprecian diferencias importantes, y en todo caso, se matiza algún aspecto de los ya mencionados. Por ejemplo, en términos de informática se define como:

Representación de objetos de una manera formalizada, adecuada para la comunicación o tratamiento por medio de individuos o automáticamente. Es la información

71 Datum $=_{\text {def. }}$. $x$ es distinto de $y$, donde $x$ y $y$ son dos variables no interpretadas y la relación de "ser distintas", así como el dominio, se dejan abiertos a futuras interpretaciones". 
que se ha procesado por un programa de computadora (digital data) o las señales continuas llamadas analógicas (analog data). ${ }^{75}$

Por otra parte, la Encyclopaedia of Information Technology, expone que el término se usa a menudo para referirse a cualquier tipo de información, ya sea un solo elemento o un conjunto y que pueda procesarse por una computadora. La clasificación que propone es la siguiente:

1. Datos de entrada y salida. Un programa resuelve una clase de problemas y los datos de entrada determinan en qué caso procesa ciertos problemas. Los datos de salida son las soluciones a los problemas.

2. Datos activos y pasivos. Los datos activos son instrucciones de un programa Los datos pasivos son el objeto de dichas actividades de procesamiento.

3. Datos numéricos y alfanuméricos. Los primeros son guarismos y algunos caracteres especiales (como los signos + y -), en tanto los datos alfanuméricos incluyen números, letras y caracteres. ${ }^{76}$

En los dos casos anteriores, la definición se hace desde el procesamiento de datos. En cambio, la International Encyclopedia of Information and Library Science, señala que además de los significados anteriores el término general dato se usa para información codificada cuantitativa o numéricamente, pero es frecuentemente empleada de manera coloquial con un sentido no totalmente diferente a "información", por ejemplo: "datos bibliográficos" o "información bibliográfica". 77

Si nos basamos en la GDI, compuesta por datos + significado, y de acuerdo con la naturaleza de los datos expuesta por Floridi, la información es como una moneda con dos caras, las cuales están unidas indisolublemente y en situación de referencia mutua. Por lo anterior, es importante revisar que menciona el autor antes citado respecto a la información como contenido semántico.

$\mathrm{Al}$ respecto, Floridi afirma que cuando los datos están bien estructurados y son significativos, el resultado se conoce como contenido semántico. La información, entendida como contenido semántico, se presenta en dos variedades: instructivas [instructional] y factuales [factual]. En cuanto a la primera, ésta transmite requerimientos mediante acciones determinadas y respecto a la segunda, dicha información representa un hecho en sí. También se destaca

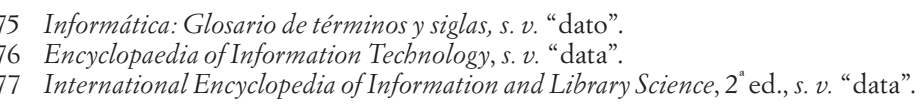


que la información como contenido semántico es declarativa o factual, además, esta última puede ser calificada como cierta o falsa. La definición que propone es la siguiente: $p$ califica como información semántica factual si y sólo si p está bien estructurada, es significativa y los datos son verídicos. ${ }^{78}$

Por lo tanto, el contenido semántico factual es la forma más común de comprender a la información. En consecuencia, Floridi concluye que una condición necesaria para el conocimiento (científico o académico) es contar información cuyo contenido semántico verdadero.

Continuando con la línea de análisis de la información como concepto de idealización o aproximación a entidades reales, y en concordancia con la revisión del contenido semántico de la información, incluido en la clasificación de Floridi, es importante abordar el concepto de información en el contexto de las teorías cognitivas, cuya preocupación está relacionada con la construcción del significado. $\mathrm{Al}$ respecto, $\mathrm{Muñoz}^{79}$ ha llamado la atención sobre lo expresado por Bruner, décadas atrás, quien confronta las repercusiones que tuvo el modelo de la teoría de la información para la psicología.

\section{INFORMACIÓN Y COGNICIÓN}

El proceso de desplazamiento fue de tal modo que Bruner lo sintetizó en la siguiente afirmación: "Algo que sucedió muy temprano fue el cambio de énfasis del 'significado H’ a la 'información, de la construcción del significado al procesamiento de la información" ${ }^{80}$ De acuerdo con lo expresado por $\mathrm{Mu}-$ ñoz, así como por el relato de Bruner, ${ }^{81}$ la pérdida del significado y el reduccionismo que implicó el nuevo concepto de información fue algo que:

[...] fue minando cada vez más no sólo la posibilidad de construir significados, sino más básicamente la capacidad para tratar con el componente semántico que posee la noción de información. Aún sin negar este punto, pero reduciéndolo cada vez más a una mera condición de ocurrencia de la información -la información se codifica en ciertas condiciones semánticas e intencionales para entrar en posiciones funcionales que pueden producir conductas-. La investigación se fue moviendo cada vez más uniformemente a posiciones donde lo mental debía de quedar eliminado, por superfluo, por innecesario para la explicación de la cognición semántica. Para ello, bastaba sólo tratar los procesos sintácticos que construyen 
cadenas de símbolos y en otros casos, la información era un resultado de niveles no significativos de procesamiento. ${ }^{82}$

Lo fundamental estaba en impulsar las teorías cognitivas para explicar el funcionamiento de los componentes semánticos en el campo de la información y su interrelación con el trabajo intelectual de la cognición y el respectivo aumento semántico. De acuerdo con el autor citado anteriormente, la respuesta la ofrece Bogdan ${ }^{83} \mathrm{y}$, como preámbulo a la síntesis que desarrolla acerca de la información cognitiva, Muñoz puntualiza lo siguiente:

1. De conformidad con la teoría computacional, la información es lo que permite decidir entre alternativas, por ello un mensaje "contiene más información en tanto nos permite eliminar un mayor número de alternativas equiprobables". ${ }^{4}$

2. La aportación basada en la discriminación no depende sólo de la cantidad de información recibida sino de la poseída. ${ }^{85}$

3. La información es caracterizada como una estructura o codificación por un organismo ante una entrada cuyo origen es una fuente exterior.

Asimismo, Muñoz destaca que en la concepción de Bogdan, la información presenta dos características gracias a las cuales es posible que se construyan actitudes proposicionales. La primera de ellas, se refiere al aspecto interno de la información y consiste en la codificación simbólica, comprensible para el organismo o sistema, de modo tal que dispone un estado concreto, y agrega:

Esta codificación interna de la información (la representación) en tanto que configura el estado del sistema es lo causalmente eficaz en el proceso de cognición. También internamente encontramos una dimensión intencional de la información representada, o en estructuras de datos, -conceptos, significaciones, prototipos, o patrones-guardados en la memoria, o bien como reglas y procedimientos. ${ }^{86}$

La segunda característica, que Bogdan designa aspecto externo de la información, caracteriza las relaciones entre las codificaciones internas,

82 Muñoz Gutiérrez, op. cit., p. 1.

83 Radu J. Bogdan, "Actitudes mentales y psicología del sentido común (contra la eliminación)".

84 Muñoz Gutiérrez, op. cit., p. 1.

85 Idem.

86 Ibid., p. 2. 
representaciones y los objetos; las representaciones lo son de estados del mundo y remiten a objetos externos. Las representaciones poseen condiciones de verdad y, por tanto, poseen condiciones de verdad. ${ }^{87}$

Cabe señalar que Bogdan ha analizado el problema de la función de la "información mental" vinculada con las actitudes mentales y, de ello, reseña lo siguiente:

Las actitudes mentales deben tener relación con la manera en que la información anima y mueve la cognición y la conducta presentes de cada uno. Y, como ya vimos, no es la información semántica como tal la que anima y mueve. Creemos y deseamos porque debemos obrar y para obrar debemos registrar la información que relaciona la acción con nuestro estado cognitivo presente. En otras palabras, tratamos la información a tendiendo a la creencia y al deseo porque esa información debe ponerse al servicio de nuestra acción y de nuestra cognición del momento. ${ }^{88}$

De acuerdo con Bogdan la información semántica no es suficiente para explicar el ámbito de la cognición y de la mente. Muñoz sintetiza la propuesta de Bogdan respecto al término información, como una noción de información mental de naturaleza pragmática funcionalmente eficaz en la cognición y en la conducta (las cursivas son del autor). También menciona que "Esta información mental añade además a la información de entrada y a su forma semántica, un aspecto incremental que incide en un ámbito pragmático y es responsable de la cognición y la conducta" ${ }^{89}$ Puesto que la función de la información incremental es relevante, Bogdan, a decir de Muñoz, menciona que tales entradas se individualizan en el momento que interactúan con el sistema, de lo cual se subraya dos elementos, a saber: primero el tema; define el área de interés y marca los límites exteriores de la incrementación potencial, además, permite articular incrementos anteriores a fin de ofrecer continuidad y relevancia. El segundo elemento es la articulación categorial; permite fijar el formato del incremento informativo. ${ }^{90}$

La individualización de la información incremental para Bogdan, de acuerdo con Muñoz, es analizada del siguiente modo:

[1] Roberto vació la botella de vino

(i) La información incremental que contienen se puede analizar relativizándola a los siguientes parámetros:

(ii) Tema: A lo que se atiende (un evento en casa) 
(iii) Información dada. Lo que se sabe (Roberto hizo algo con la botella de vino).

(iv) Incertidumbre: identidad de acción (¿Qué hizo Roberto a la botella de vino?).

(v) Proyecciones: una clase relevante de alternativas (la vació, jugo con [sic], rompió, etc.).

(vi) Inferencia: valor para la nueva información (la vació).

(vii) Articulación categorial: Agente-Acción-Objeto.

(viii) Integración: nueva información (la vació) es la información dada (Roberto hizo algo con la botella), lo que produce una información terminal (Roberto vació la botella de vino). ${ }^{91}$

En esta línea de análisis, la pragmática de la cognición y de la conducta se sustentan en este modelo de trabajo intelectual, lo cual también incluye la fijación de la información mental y que implica la interacción con una representación objetiva "y fijan una nueva información en el conocimiento atendiendo a lo que ya se sabe, espera o quiere hacer". ${ }^{2}$

Así, tenemos que la información en el contexto de la cognición, asume diferentes denominaciones de acuerdo con la función que cumple (entrada, incremental, terminal) y su naturaleza pragmática es imprescindible para las actitudes mentales, el obrar humano y la cognición.

Por otra parte, se han desarrollado diversas teorías de la arquitectura de lo mental, las cuales incluyen el término información pero que superan con mucho el modelo computacional de procesamiento de información, el cual resulta limitado para explicar el sistema global de mecanismos que se requieren para exhibir una conducta flexible e inteligente. ${ }^{93}$

Las limitaciones del modelo de procesamiento de información, son más evidentes cuando se revisa la arquitectura que engloba las características, propiedades, modo de procesamiento y limitaciones de los sistemas cognitivos reales y que, según Ezquerro, abarca:

1. Comportarse de forma flexible en función del entorno.

2. Exhibir una conducta adaptativa (racional, orientada a metas).

3. Funcionar en tiempo real.

4. Operar en un entorno rico, complejo y detallado:
a. Percibir una inmensa cantidad de detalles cambiantes;
b. Utilizar grandes cantidades de conocimiento;
c. Controlar un sistema motor con muchos grados de libertad

91 Ibid., p. 4.

92 Idem.

93 Véase Jesús Ezquerro, "Teorías de la arquitectura de lo mental” y Bruner, op. cit. 
5. Utilizar símbolos y abstracciones

6. Utilizar lenguajes tanto naturales como artificiales.

7. Aprender del entorno y de la experiencia.

8. Adquirir capacidades en el curso del desarrollo.

9. Vivir de forma autónoma dentro de la comunidad social.

10. Exhibir auto-conciencia y sentido del yo. ${ }^{94}$

Una arquitectura mental capaz de explicar el sistema cognitivo, es de gran relevancia para la disciplina bibliotecológica, ya que abre grandes desafíos para comprender e interactuar a partir la información incremental (en los términos de Bogdan), así como la fijación de nuevas informaciones en los sistemas cognitivos.

\section{INFORMACIÓN Y BIBLIOTECOLOGÍA}

En el campo bibliotecológico el término información es imprescindible y su uso se ha extendido enormemente ya que la ciencia de la información durante varias décadas ha realizado investigación aplicada en las bibliotecas y unidades de información, además de un gran desarrollo de programas para el registro de materiales gráficos, además de los sistemas de control y gestión organizacional.

Conviene recordar brevemente que en los Estados Unidos, la Ciencia de la Información oficialmente reemplazó a la Documentación a finales de 1960 y que, según Lilley y Trice:

The architects of information science in the United States wanted to be sure that it would no longer be mistaken either for the microfilm-oriented discipline that documentation had become or for the document-oreinted discipline that was library science. This new discipline would be free or real or imagined apppendages. ${ }^{95}$

Los autores anteriores destacan también que en muchas partes del mundo, la documentación y la bibliotecología coexisten y a veces se fusionan en asociaciones profesionales y publicaciones, como en el caso británico, sin embargo, en los Estados Unidos no se han fusionado en asociaciones ni en publicaciones periódicas especializadas o índices. ${ }^{96}$ En paralelo,

94 Ezquerro, op. cit., p. 109.

95 "Los fundadores de la Ciencia de la Información de los Estados Unidos quisieron asegurarse que no se confundiera más con una disciplina orientada por el microfilm, como lo era la documentación, o por una disciplina enfocada en los documentos, como lo era la bibliotecología. Esta nueva disciplina estaría libre de apéndices reales o imaginarios". Dorothy B. Lilley y Ronald W. Trice, A history of Information Science 1945-1985, p. 3. 
de acuerdo con Lilley y Trice, ha sucedido que la ciencia de la información aboga por no ser identificada con los bibliotecarios y se ha cambiando el vocabulario tradicional; por otra parte, la mayor parte de los bibliotecarios, no quieren ser vencidos por quienes son partidarios de la alta tecnología.

Information Science también presentó una terminología que difería notablemente de la bibliotecología o la documentación, por ejemplo: recuperación de información, descriptores o términos, relevancia, precisión, exhaustividad (recall), lógica booleana, así como, resúmenes e indización.

De acuerdo con el relato histórico que hacen los autores citados, se observa que conceptualmente el término información se introdujo como una innovación conceptual, aunque no necesariamente bienvenida, en un ámbito disciplinario especialmente fértil como es el caso de la bibliotecología.

La postulación de la ciencia de la información pudo interpretarse como la superación de un estudio fenoménico centrado en el libro o el documento hacia un nivel substancial o abstracto representado por la información y el ciclo de la información; ambos conceptos superaban con mucho los referentes físicos inmediatos, de tal forma que si el concepto de documento poseía mayor capacidad de inclusión respecto al término libro, de igual modo, el término información mostraba un concepto abstracto y con posibilidades ilimitadas de incluir diversidad de referentes materiales, como libros, revistas, archivos, etc.

Autores como Rubin han mencionado que la ciencia de la información enriqueció considerablemente el vocabulario y la teoría de la ciencia bibliotecológica. Incluso, mejoró la comprensión del trabajo de las bibliotecas y las unidades de información con la sociedad. La definición clásica de ciencia de la información que presenta es la siguiente:

$[\ldots]$ the science that investigates the propieties and behavior of information, the forces governing the flow of information, and the means of processing information for optimum accesibility and usability. The processes incluye the origination, dissemination, collection, organization, storage, retrival, interpretation, and use of information. The field is derived from or related to mathematics, logic, linguistics, psicology, computer tecnology, operation research, the graphic arts, comunication, library science, management, and some other fields. ${ }^{97}$

97 "Ciencia que investiga las propiedades y comportamiento de la información, las fuerzas que rigen el ciclo de la información y el sentido del procesamiento de la información para una óptima accesibilidad y usabilidad. El proceso incluye la creación, la diseminación, la recopilación, la organización, el almacenamiento, la recuperación, la interpretación y el uso de la información. El campo se deriva de, o está relacionado con las matemáticas, la lógica, la lingüística, la psicología, la tecnología computacional, la investigación de operaciones, las artes gráficas, la ciencia de la comunicación, la bibliotecología, la administración y algunos otros campos". Richard E. Rubin, Foundations of Library an Information Science, p. 31. 
En la disciplina bibliotecológica, desde hace décadas, y en virtud de la adopción de los términos de la ciencia de la información, se ha observado que el término información funciona para hacer referencia también a los datos o al conocimiento y se ha subsumido la importancia de los soportes materiales. Si revisamos lo que expone Rubin constataremos que resulta reiterativo respecto a lo visto hasta ahora; por ejemplo, dice que el término de "dato" se usa como sinónimo de información, aunque su característica principal es la de conformar los bloques de la información y del conocimiento, es decir, el material con el cual se construye la información. Se representa a través de los números, las letras o símbolos, sin embargo, en los datos está ausente el significado, o bien, no ha sido asignado.

En cuanto al término información señala que la definición es compleja, pero deja en claro que para la ciencia bibliotecológica la información significa adición de datos, organización o clasificación con significado, lo que a su vez implica algún tipo de procesamiento o comprensión. ${ }^{98}$

Por su parte, Saracevic ${ }^{99}$ considera que la evolución de la ciencia de la información ha dado claridad para entenderla no a partir de la información como tal, sino a través de la solución de problemas relacionados con la comunicación del conocimiento y los registros del mismo, obviamente entre los seres humanos cuyos contextos son sociales, institucionales, o bien, de uso individual o entrado en necesidades de información.

Desde los años setenta del siglo XX, autores tan importantes como Shera promovieron nuevos conceptos para sustituir uno de los referentes básicos de la bibliotecología, como es el caso de "libro". Al respecto, Shera denomina al libro como sinónimo de registro gráfico. ${ }^{100}$ Es relevante este intento de abstracción ya que posteriormente el término registro adquirirá, al igual que el de información, un carácter imprescindible en la literatura y los modelos explicativos de la bibliotecología, tal y como quedó de manifiesto en Saracevic.

Cabe preguntarse por qué Shera asocia los términos antes señalados y la respuesta está basada en que, según dicho autor, la biblioteca es un organismo de comunicación secundaria, particularmente de comunicación gráfica, que a su vez forma parte del principal proceso social: la comunicación. De lo anterior se desprende que el bibliotecario en la sociedad sea el mediador entre el hombre y sus registros gráficos. En este contexto, el objetivo de la biblioteca es juntar, preservar y hacer disponibles para el uso los registros de la experiencia humana. En consecuencia, la experiencia humana queda 
registrada, en lo fundamental, gráficamente. Para Shera, el trabajo de la disciplina bibliotecológica tiene sentido en la medida que sirve a la cultura. ${ }^{101}$

Por otra parte, en la tradición académica bibliográfica y debido al nuevo contexto de las tecnologías de la información sucedieron cambios conceptuales de gran trascendencia. Vale la pena revisar la síntesis que hace Rodríguez García ${ }^{102}$ de dicho cambio, pues expone que el cambio fundamental se da de las entidades bibliográficas a las entidades de información e incluso a las nuevas entidades de información. En cuanto a la primera de estas entidades menciona que son la unidad central del universo bibliográfico, la cual queda constituida por un conjunto de ejemplares que pueden ser descritos y representados en un registro bibliográfico. Así, pues, estas unidades representan una porción del universo bibliográfico interdependiente. Según Rodríguez García, ${ }^{103}$ el modelo conceptual bibliográfico abarca siete entidades, a saber: documentos, obra, superobras, ediciones, autores, temas y otras entidades.

Por lo que se refiere a las entidades de información, se destaca que la incorporación de Internet y de dispositivos de cómputo ha sido el origen de estas entidades. Se ha propuesto sustituir el término entidades bibliográficas por el concepto entidades cargadas de información electrónica, también denominadas paquetes de información. Estas entidades son una extensión de las entidades bibliográficas, sin embargo son también nuevos formatos con una poderosa capacidad de resguardar información.

Por su parte, las nuevas entidades de información, deberán entenderse como recursos derivados de las aplicaciones tecnológicas cuya naturaleza es más interactiva y dinámica, con capacidad de combinarse con entidades que pertenecen a otros recursos. Además se caracterizan por ser fragmentadas y gracias a ello es posible acceder y usar la información que contienen. ${ }^{104}$ Los términos relacionados con las nuevas entidades de información son los siguientes: objetos informativos o fuentes de información, recursos electrónicos, publicaciones electrónicas o digitales, documentos o documentos digitales y objetos de información digital. Ante tal gama de términos Rodríguez García agrega que la nueva entidad:

[...] ha nacido en un soporte y un medio digital; es decir, como un objeto intangible y por tanto deja de ser tocable como lo es el libro, de ahí que su entorno, como su propia constitución, esté dominado por el aspecto electrónico y se considere como objeto digital. Este objeto y la información digital, en general, están basados

101 Ibid., p 190.

102 Ariel Alejandro Rodríguez García, Las nuevas entidades de información analizadas desde la perspectiva de la organización de la información.

103 Ibid., p. 7.

104 Ibid., p. 20 
en los dos distintos estados que se encuentran en el código binario, principal medio que permite representar los números, los textos, imágenes, sonidos e instrucciones, cuya existencia es posible gracias al almacenamiento que hace la computadora en sus archivos por periodos breves o largos. ${ }^{105}$

Queda claro que en la discusión actual de los objetos de estudio de la bibliotecología no sólo el concepto de información, nacido de la teoría de la información de Shannon, sino además el contexto de las tecnologías de la información han reconfigurado los modelos normativos bibliotecológicos para representar y organizar el universo de registros que contienen información socialmente valiosa.

Por último, vale la pena considerar que en las nuevas pautas de catalogación conocidas como RDA (Recursos, Descripción y Acceso) ${ }^{106}$ el énfasis está dado en el término recurso, que a su vez está asociado a manifestación o ítem, entidades individuales, agregados y componentes de tales entidades, así como a entidades tangibles e intangibles. ${ }^{107}$ Como se sabe, las normas de catalogación han permitido la descripción y acceso a los recursos, sin embargo, el gran reto es rediseñarlas para el mundo digital.

En resumen, puede señalarse que el tránsito se ha dado de la entidades bibliográficas a las entidades de información y, en este momento, ha culminado con los recursos del mundo digital, cuyo referente fundamental son las tecnologías de información. Lo anterior sin dejar de lado, por una parte, las formas de observar la sociedad como sistema, sociedad red o sociedades del conocimiento, y, por la otra, explicar la cognición humana a partir de la interacción con la información.

\section{Conclusiones}

Las dimensiones del concepto información son múltiples y cada una de ellas ha repercutido, desde varios frentes y de un modo u otro, en la disciplina bibliotecológica. Lo anterior se explica porque el concepto información ha sido esencial en diversas teorías - de la propia información, sociológicas y cognoscitivas-, y aunque su uso ha sido fundamentalmente ficcional y metacientífico, se aprecia que su utilidad intrateórica ha sido avasalladora.

Desde su origen en la teoría de la información, este término permitió, como en el caso de la bibliotecología, introducir niveles de análisis más 
abstractos o substanciales. En consecuencia, se incorporó como un progreso conceptual y aportó modelos explicativos que enriquecieron la perspectiva marcadamente normativa que durante varias décadas ha predominado en la disciplina. No obstante, se ha llegado al extremo de reducir o subsumir las entidades fundamentales de la bibliotecología a dicho término, lo cual también se ha visto favorecido por el empleo de las tecnologías de información y procesamiento de la misma. Afortunadamente, tal subsunción ha comenzado a difuminarse.

Es de subrayarse que las diversas dimensiones o concepciones que han acompañado al término información, así como el estudio social de las tecnologías que la acompañan, han dejado en claro la necesidad de emprender estudios interdisciplinarios gracias a los cuales sean abordados nuevos problemas en los cuales está implicada la disciplina bibliotecológica, tales como: la organización de recursos de información y servicios, la desigualdad social y las brechas cognoscitivas, el desarrollo humano y la justicia, así como de identidad cultural y mundialización.

De igual modo, se hace presente el requerimiento metodológico de identificar con precisión teórica cómo se utiliza el concepto información, ya que su uso indiscriminado lo ha llevado a extremos de sobrevaloración, banalización o bien lo ha restringido a un contexto de comunicación electrónica. En todo caso, es claro que para la disciplina bibliotecológica su impacto teórico y aplicado lleva varias décadas, y aunque difícilmente en el futuro se utilice este término de modo aislado, es importante ser muy cuidadosos con el alcance explicativo o descriptivo que se pretenda dar, ya que cada vez es más frecuente su presencia en la reconfiguración de las entidades de estudio bibliotecológico y el entorno en que se lleva a cabo su intervención social.

\section{BibLIOgRAFÍA}

American Library Association, The Information Literacy Competency Standards for Higher Education, Chicago, Ilinois, 18 de enero de 2000.

Bateson, Gregory, Espiritu y naturaleza, Buenos Aires, Amorrortu, 1982.

Bawden, David y Lyn Robinson, An Introduction to Information Science, London, Facet Publishing, 2012.

Bogdan, Radu J., "Actitudes mentales y psicología del sentido común (contra la eliminación)", en Psicología ordinaria y ciencias cognitivas, Barcelona, Gedisa, 1993, pp. 72-111.

Bruner, Jerome, Actos de significado: más alla de la revolución cognitiva, Madrid, Alianza, 1991. 
Campbell, Jeremy, El hombre gramatical, México, Fondo de Cultura Económica, 1989.

Castells, Manuel, La era de la información: economía, sociedad y cultura, 3 vols., México, 1999.

Conceptions of Library and Information Science: Historical, empirical and theoretical perspectives, Pertti Vakkari y Blaise Cronin (eds.), 314, London, 1992.

Ezquerro, Jesús, “Teorías de la arquitectura de lo mental”, en La mente bumana, Madrid, Trotta, Consejo Superior de Investigaciones Científicas, 1995, pp. 97-150.

Floridi, Luciano, Information: a very short introduction, New York, Oxford University Press, 2010.

Lilley, Dorothy B. y Ronald W. Trice, A bistory of Information Science 1945-1985, Academic Press, 1989.

Luhmann, Niklas, Introducción a la teoría de sistemas: lecciones publicadas por Javier Torres Navarrete, introd. de Javier Torres Navarrete, México, Universidad Iberoamericana, Antrophos, Iteso, 1996.

— , Organización y decisión, pról. de Darío Rodríguez Mansilla, España, Herder, 2010.

Moulines, Ulises, "Conceptos teóricos y teorías científicas", en La ciencia: estructura y desarrollo, vol. 4, Madrid, Trotta, Consejo Superior de Investigaciones Científicas, 1993, pp. 147-162.

Muñoz Gutiérrez, Carlos, Modelos narrativos de la mente, tesis de doctorado, Universidad Complutense de Madrid, 1995.

Rodríguez García, Ariel Alejandro, Las nuevas entidades de información analizadas desde la perspectiva de la organización de la información, México, Centro Universitario de Investigaciones Bibliotecológicas/UNAM, 2010.

Rubin, Richard E., Foundations of Library an Information Science, New York, Neal-Schuman Publishers, 2004.

Saracevic, Tefko, "Information science: origin, evolution and relations", en Conceptions of Library and Information Science: Historical, empirical and theoretical perspectives, London, Taylor Graham, 1992, pp. 5-25.

Shera, Jesse, Los fundamentos de la educación bibliotecológica, México, UNAM, Centro Universitario de Investigaciones Bibliotecólogicas, 1990.

Unesco, Informe mundial de la Unesco: Hacia las sociedades del conocimiento, París, Unesco, 2005.

Vélez Cuartas, G., "Las redes de sentido como modelo para la conservación de la ciencia: Luhmann desde un punto de vista estructural", en La teoría de los sistemas de Lubmann a prueba: borizontes de aplicación en la investigación social en América Latina, México, El Colegio de México, Centro de Estudios Sociológicos/UNAM, Instituto de Investigaciones Sociales/UNAM, 2012, pp. 219-274. 
EL CONCEPTO DE INFORMACIÓN: DIMENSIONES BIBLIOTECOLÓGICA, SOCIOLÓGICA Y COGNOSCITIVA

Vickery, Brian y Alina Vickery, Information Science in Theoria and Practice, K. G. Saur, 2004.

$\infty$ 